attempt, only 300 tons of iron were produced in seven years at a cost of $50,000 \mathrm{l}$. A study of the entire book shows that at the moment barytes is practically the only mineral of serious economic importanee that Ireland is capable of producing. Apart, however, from the strictly commercial aspect of the subject, Prof. Cole's work is of great value to the student of mineral deposits, inasmuch as it supplies authentic information concerning the mineral resources of the country.

\section{Overzicht van de theorie en de toepassingen van gassen, waarin de onderlinge botsingen der moleculen kunnen} verwaarloosd worden. Door Dr. Jos. ter Heerdt. Pp. vii +324. (Utrecht and Nijmegen: N. V. Dekker \& Van de Vegt en J. W. van Leeuwen, r923.) 6.50 florins.

Since the classic researches of Maxwell on the internal friction of gases and those of Crookes on radiometer theory, no investigations have been so important in connexion with the kinetic theory of gases as the work of Martin Knudsen on the properties of highly rarefied gases, in which the mutual collisions of the molecules may be neglected. Dr. Jos. ter Heerdt has produced a very clear monograph in which the work of Knudsen and that of some other investigators, Soddy and Berry, Gaede, Langmuir, Weber, etc. (scattered in many periodicals), is brought together and critically discussed.

After a short historical introduction and some general considerations regarding the kinetic theory of gases, (Chap. I.), the author deals in the following chapters with molecular flow through narrow capillaries and small holes in plates, with molecular flow through tubes with a temperature gradient (pressure equilibrium between two reservoirs at different temperatures, connected by a capillary tube), with the molecular conduction of heat and the coefficient of accommodation. The treatment of the problem of accommodation, as given in Chap. VI., is new and throws a new light on the question. Nevertheless no general solution is given of this very complicated problem: Chap. V. deals with the radiometer force and with the formula which Knudsen has deduced for it. In Chap. VII. a full and detailed description is given of modern high vacuum pumps, based on the principles of the kinetic theory of rarefied gases (Gaede, Langmuir) and of different kinds of high vacuum manometers. The book ends with a very complete bibliography.

The volume forms a readable and clearly written monograph on a subject not covered by any existing work and may be highly recommended to all who are interested in this subject. It is to be hoped that the book, which is published in Dutch, will be translated into English, French or German in order that it may reach a wider circle of readers. C. A. Crommelin.

Hawaiki: the Original Home of the Maori. With a Sketch of Polynesian History. By S. Percy Smith. Fourth edition. Pp. $288+20$ plates. (Auckland, Melbourne and London: Whitcombe and Tombs, Ltd., r92i.) I2s. 6 d.

IT is most fortunate that Mr. Percy Smith was able to publish the fourth and authoritative edition of this book before his death, as it contains a considerable amount of new material and of revised conclusions.
It represents the gleaning of a long life spent in amassing new data, and laboriously sifting and collating existing information. All students of oceanic ethnology owe a great debt to this painstaking, kindly, and learned pioneer. Mr. Smith entirely justifies his reliance on the general accuracy of tradition, and he has been able to give approximate dates to events in unwritten history, and also to trace three main migrations into the Pacific from Indonesia, and numerous migrations within the Polynesian area. Constructive work of this kind on imperfect material is necessarily open to criticism, but Mr. Smith courageously attempts to interpret hints and obscure words, and by imagination, controlled by intimate knowledge of Polynesian ethnology, he has made a plausible connected story, which, in his concluding words, "will in the meantime serve the purpose of a summary of the history of the people, on which others may build."

The Indian dates on p. 85 require revision. The Sâka entered the Panjab about 75 B.C., not 95 B.c.; the great colonisations of Java from India are also placed much too early; according to Havell they were due to the final collapse of the Sâka power at the beginning of the fifth century. It is important to have correct dates for events in India, as Mr. Smith uses them in the development of his thesis. The view that the Polynesians may have been in part a branch of the "ancient Gangetic race" has much to" recommend it, but by terming them "Proto-Aryan" he raises very grave difficulties, but, perhaps, Pre-Aryan is what he meant to express.

This little book is invaluable to all those who take an interest in the history of the most intrepid explorers of the Pacific.

A. C. HADDON.

Expressionism in Art: Its Psychological and Biological Basis. By Dr. Oskar Pfister. Authorised translation by Barbara Low and Dr. M. A. Mugge. Pp. viii +272 . (London: Kegan Paul and Co., Ltd., I922.) $6 s .6 d$. net.

DR. Pfister's work is a study by psycho-analytic methods of a French artist suffering from depression, who came to the author for psychological treatment. In addition to the analysis of his dreams, the artist was asked to draw whatever he liked, and these drawings, usually of an extremely unconventional character, were treated in the same way as the dreams. The results are very interesting, both from the insight obtained into the personality of the artist and also from the light thrown on that type of art generally known as expressionism.

The first part of the book is a study from a psychological point of view of the artist; the second part discusses the psychological and biological background of expressionism. The author shows how excellent for diagnostic purposes were the piciures which invariably represented the artist's psychical state. From a study of the pictures of other expressionists, he concludes that all expressionists carry into their work a number of infantile characteristics. Instead of attempting to understand the external world, they turn away and represent their own internal conflicts in phantasy form, their pictures thus being in reality self-portraits. If pushed to its logical extremes, expressionism would result in an absolute rejection 